\title{
Synthesis and Characterization of New Highly Soluble Polyamides Derived from $\alpha, \alpha^{\prime}$-Bis[3,5-dimethyl-4-(4-aminophenoxy)phenyl]- 1,4-Diisopropylbenzene
}

\author{
Der-Jang Liaw ${ }^{\dagger}$ Hung-Ping Huang, Pei-Nan Hsu, and Wen-Hsiang CHeN \\ Department of Chemical Engineering, National Taiwan University of Science and Technology, \\ Taipei 106, Taiwan
}

(Received May 9, 2001; Accepted March 11, 2002)

\begin{abstract}
The five benzene rings-containing diamine, $\alpha, \alpha^{\prime}$-bis[3,5-dimethyl-4-(4-aminophenoxy)phenyl]-1,4diisopropylbenzene (BDAPD) was prepared by the aromatic nucleophilic substitution of $\alpha$, $\alpha^{\prime}$-bis(4-hydroxy-3,5dimethylphenyl)-1,4-diisopropylbenzene with 1-chloro-4-nitrobenzene, and subsequent hydrogenation of the intermediate dinitro compound. The diamine was reacted with various aromatic dicarboxylic acids to prepare a series of new polyamides. The polyamides were produced with high yield and inherent viscosities of $0.68-0.94 \mathrm{dL} \mathrm{g}^{-1}$. The wideangle X-Ray diffraction diagrams revealed that all the polyamides showed amorphous character. All of the polyamides showed excellent solubility in a variety of solvents such as $N$-methyl-2-pyrrolidinone, $\mathrm{N}, \mathrm{N}$-dimethylacetamide, $\mathrm{N}, \mathrm{N}$ dimethylformade, dimethyl sulfoxide, pyridine, cyclohexanone, and tetrahydrofuran. These five benzene ringscontaining polyamides had better solubility than those containing only one isopropylidene unit or a hexafluoroisopropylidene linkage in the repeating unit of polyamide backbone. These polyamides had glass transition temperatures $\left(T_{\mathrm{g}}\right.$ 's $)$ between $237-256^{\circ} \mathrm{C}$. The thermogravimetric analyses demonstrated that almost all of the polymers were stable up to $400^{\circ} \mathrm{C}$, and the $10 \%$ weight loss temperatures were recorded in the range $437-452^{\circ} \mathrm{C}$ and $447-463^{\circ} \mathrm{C}$ in nitrogen and air atmosphere, respectively.

KEY WORDS $\quad \alpha, \alpha^{\prime}$-Bis[3,5-dimethyl-4-(4-aminophenoxy)phenyl]-1,4-diisopropylbenzene (BDAPD) / Polyamides / Isopropylidene /
\end{abstract}

Aromatic polyamides have already been reported for their high temperature resistance and excellent mechanical properties. ${ }^{1,2}$ However, wholly aromatic polyamides, particularly those with para substituted rings, are quite intractable materials that do not melt and only dissolve in strong mineral acids such as concentrated sulfuric acid or in very polar aprotic solvents containing salts. Therefore, many efforts have been made to chemically modify the structure of these polymers with the aim of improving their solubility and/or lowering their transition temperatures to a range which facilitates their processing in melt.

Approaches investigated in attempting to improve the solubility of polyamides include the addition of pendent groups to the polymeric backbone $\mathrm{b}^{3-5}$ and the incorporation of bulky substituents ${ }^{6-9}$ or flexible units $^{10,11}$ within the parent chain.

A successful approach to improve the processability of aromatic polyamide without extreme loss of their outstanding properties is to introduce flexible ether and isopropylidene units into the polymer backbone. Such flexible polyamides are known to exhibit reasonable thermal stability and good mechanical properties together with excellent moldabiltiy. Our pre- vious works observed that the solubility of polyamides, ${ }^{12}$ polyimides, ${ }^{13}$ and polyamide-imides ${ }^{14,15}$ was enhanced by incorporating the ether and isopropylidene units into the polymer backbone while retaining a satisfying thermal stability.

In this study the diamine, $\alpha, \alpha^{\prime}$-bis[3,5-dimethyl4-(4-aminophenoxy)phenyl]-1,4-diisopropylbenzene (BDAPD) containing flexible ether and isopropylidene units, and five benzene rings was synthesized and used to prepare a series of polyamides. Due to the presence of the flexible moieties on the polyamide backbone, there was a considerable decrease in the rigidity of polymer chain, which could be considered to be reduced the crystallinity and improved the solubility of polymer. Therefore, the diamine BDAPD would be a potential monomer for preparation of soluble polyamide. In the present article, we describe the synthesis and characterization of new polyamides derived from BDAPD by using various aromatic dicarboxylic acids. The solubility, crystallinity, thermal and mechanical properties are also investigated herein.

${ }^{\dagger}$ To whom correspondence should be addressed (Phone: +886-2-27376638 or +886-2-27335050, Fax: $+886-2-23781441$ or $+886-2-$ 27376644, E-mail: liaw@ch.ntust.edu.tw, liaw8484@yahoo.com.tw). 


\section{EXPERIMENTAL}

\section{Materials}

$\alpha, \alpha^{\prime}$-Bis(4-hydroxy-3,5-dimethylphenyl)-1,4-diisopropylbenzene (from TCI), $p$-chloronitrobenzene (from Merck), anhydrous potassium carbonate (from Merck), hydrazine monohydrate (from Merck), and $10 \%$ palladium on activated carbon $(\mathrm{Pd} / \mathrm{C}$, from Merck) were used as received. Reagent-grade aromatic dicarboxylic acids such as terephthalic acid (DA1), 5-tert-butylisophthalic acid (DA2), 2,6-naphthalenedicarboxylic acid (DA3), 4,4'-biphenyldicarboxylic acid (DA4) were commercially available. 2,2'-Dimethyl-4,4'-bis(4-carboxyphenoxy)biphenyl (DA5) and 8,8-bis[4-(4-carboxyphenoxy)phenyl] tricyclo[5.2.1.0 $\left.{ }^{2,6}\right]$ decane (DA6) were synthesized according to the procedure reported in the studies. ${ }^{17,18} \mathrm{~N}, \mathrm{~N}$-Dimethylformamide (DMF), $N, N$-dimethylacetamide (DMAc) and pyridine were purified by distillation under reduced pressure before used. Acetic anhydride was purified by vacuum distillation.
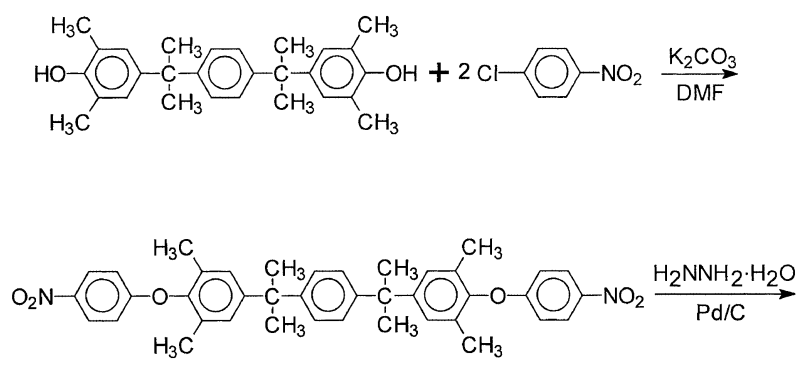

BDNPD

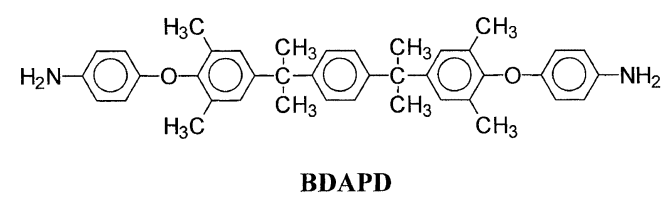

Scheme 1. Synthesis of diamine BDAPD.

$\alpha, \alpha^{\prime}$-Bis[3,5-dimethyl-4-(4-nitrophenoxy)phenyl]-1, 4-diisopropylbenzene (BDNPD). BDNPD was synthesized by the reaction of $\alpha, \alpha^{\prime}$-bis(4-hydroxy-3,5dimethylphenyl)-1,4-diisopropylbenzene $8.05 \mathrm{~g} \quad(20$ $\mathrm{mmol})$ and $p$-chloronitrobenzene $6.93 \mathrm{~g}(44 \mathrm{mmol})$ in the presence of potassium carbonate $6.08 \mathrm{~g}(44 \mathrm{mmol})$ and $20 \mathrm{~mL}$ of DMF at $160^{\circ} \mathrm{C}$ for $8 \mathrm{~h}$. The solution was then cooled and poured into methanol-water mixture. The crude product was recrystallized from glacial acetic acid to provide yellow crystal. Mp 226-227 ${ }^{\circ} \mathrm{C}$; yield : $80 \%$. The IR spectrum $(\mathrm{KBr})$ exhibited absorptions at 1579 and $1334 \mathrm{~cm}^{-1}\left(\mathrm{NO}_{2}\right)$, $1239 \mathrm{~cm}^{-1}(\mathrm{C}-\mathrm{O}-\mathrm{C}) .{ }^{1} \mathrm{H} \mathrm{NMR}\left(\mathrm{CDCl}_{3}\right): \delta(\mathrm{ppm})=8.71$ (d, 4H), $7.24(\mathrm{~s}, 4 \mathrm{H}), 6.97(\mathrm{~s}, 4 \mathrm{H}), 6.84(\mathrm{~d}, 4 \mathrm{H}), 2.04$ $(\mathrm{s}, 12 \mathrm{H}), 1.68(\mathrm{~s}, 12 \mathrm{H}) ;{ }^{13} \mathrm{C}$ NMR $\left(\mathrm{CDCl}_{3}\right): \delta$ $(\mathrm{ppm})=164.1,149.3,148.9,148.5,142.9,130.5$, 128.4, 126.9, 126.8, 115.3, 41.7, 30.3, 15.6.

ANAL. calcd for $\mathrm{C}_{40} \mathrm{H}_{40} \mathrm{O}_{6} \mathrm{~N}_{2}: \mathrm{C}, 74.51 \% ; \mathrm{H}, 6.25 \%$; $\mathrm{N}, 4.34 \%$; found : C, $74.59 \%$; H, 6.32\%; N, 4.37\%.

$\alpha, \alpha^{\prime}$-Bis[3,5-dimethyl-4-(4-aminophenoxy)phenyl]1,4-diisopropyl-benzene (BDAPD). The obtained dinitro compound BDAPD $5.0 \mathrm{~g}(7.76 \mathrm{mmol}), 0.03 \mathrm{~g}$ of $10 \% \mathrm{Pd} / \mathrm{C}$, and $25 \mathrm{~mL}$ ethanol were introduced into a three-necked flask to which $7 \mathrm{~mL}$ of hydrazine monohydrate was added dropwise at $85^{\circ} \mathrm{C}$. After the addition was complete, the reaction was continued at reflux temperature for another $24 \mathrm{~h}$. The mixture was then cooled and filtered. The crude product was recrystallized from 1,2-dichlorobenzene twice to provide BDAPD. Mp $224-226^{\circ} \mathrm{C}$; yield: $72 \%$. The IR spectrum (KBr) exhibited absorptions at 3420 and 3342 $(\mathrm{N}-\mathrm{H}), 1218 \mathrm{~cm}^{-1}(\mathrm{C}-\mathrm{O}-\mathrm{C}) .{ }^{1} \mathrm{H}$ NMR (DMSO- $\left.d_{6}\right): \delta$ $(\mathrm{ppm})=7.14(\mathrm{~s}, 4 \mathrm{H}), 6.94(\mathrm{~s}, 4 \mathrm{H}), 6.48(\mathrm{~d}, 4 \mathrm{H}), 6.41$ (d, 4H), $4.64(\mathrm{~s}, 4 \mathrm{H}), 1.98(\mathrm{~s}, 12 \mathrm{H}), 1.62(\mathrm{~s}, 12 \mathrm{H})$; ${ }^{13} \mathrm{C}$ NMR (DMSO- $\left.d_{6}\right): \delta(\mathrm{ppm})=150.6,150.0,148.7$, 147.5, 144.2, 131.0. 128.1, 127.1, 115.9, 115.6, 41.5, $30.4,16.0$.

ANAL. calcd for $\mathrm{C}_{40} \mathrm{H}_{44} \mathrm{O}_{2} \mathrm{~N}_{2}: \mathrm{C}, 82.15 \% ; \mathrm{H}, 7.58 \%$; N, $4.79 \%$; found : C, $82.03 \%$; H, 7.24\%; N, 4.45\%.
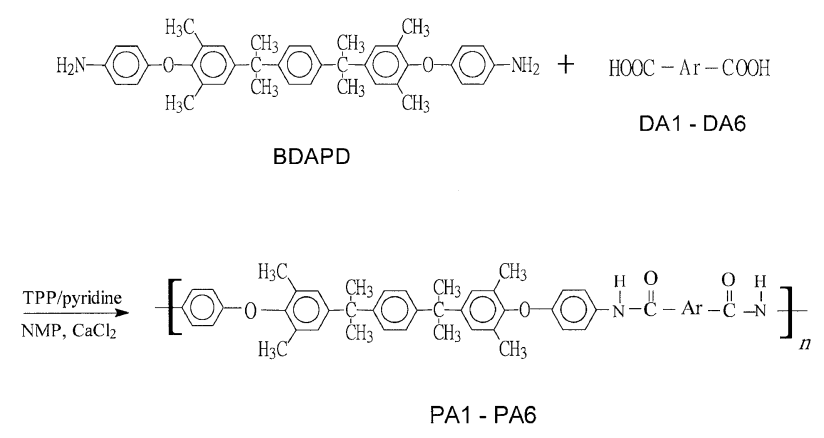

Ar:
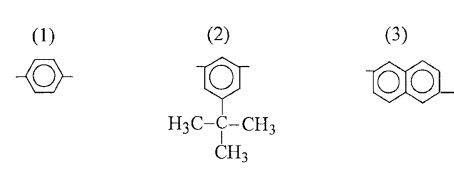

(4)
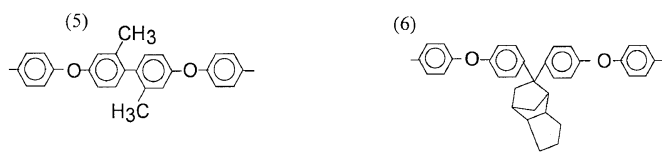

Scheme 2. Preparation of various new polyamide.

A mixture of $0.5848 \mathrm{~g}(1.0 \mathrm{mmol})$ of diamine BDAPD, $0.1661 \mathrm{~g}(1.0 \mathrm{mmol})$ of diacid DA1, $0.4 \mathrm{~g}$ of calcium chloride, $0.8 \mathrm{~mL}$ of triphenyl phosphite, $0.8 \mathrm{~mL}$ of pyridine, and $4 \mathrm{~mL}$ of NMP was heated with stirring at $100^{\circ} \mathrm{C}$ for $3 \mathrm{~h}$ under nitrogen stream. After cooling, the reaction mixture was poured into a 

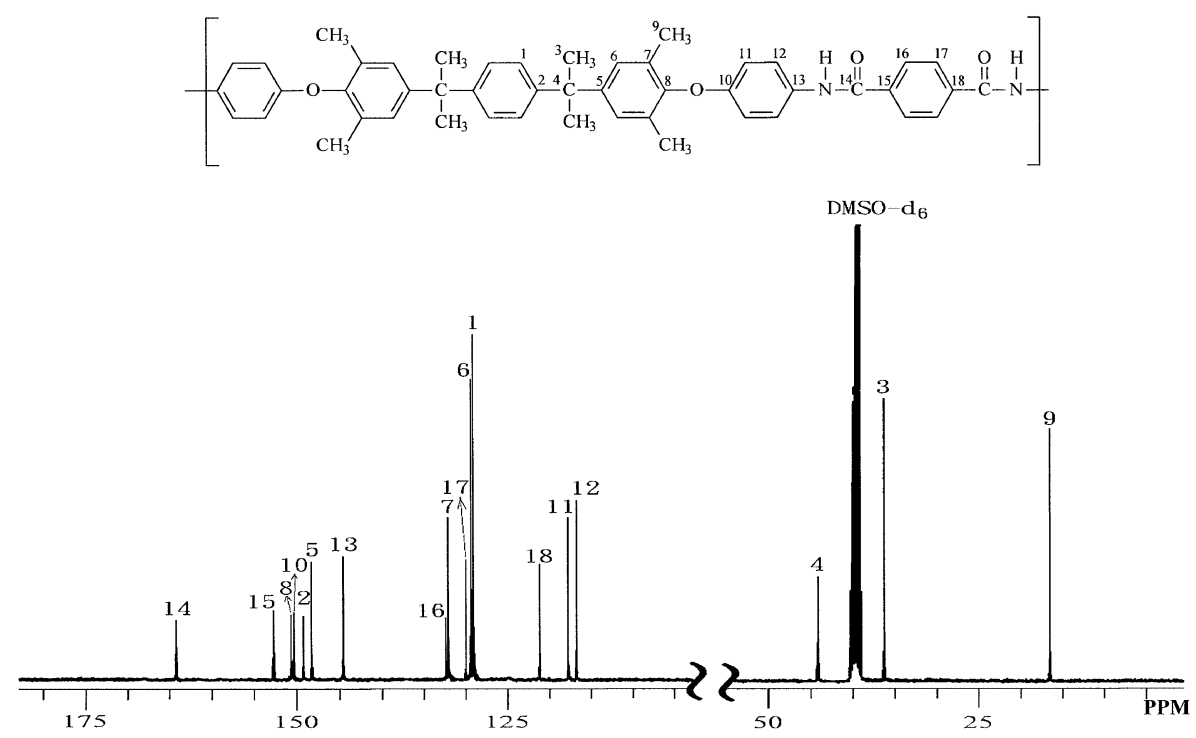

Figure 1. $400 \mathrm{MHz}{ }^{13} \mathrm{C}$ NMR spectrum taken in DMSO- $d_{6}$ at $25^{\circ} \mathrm{C}$ for PA1.

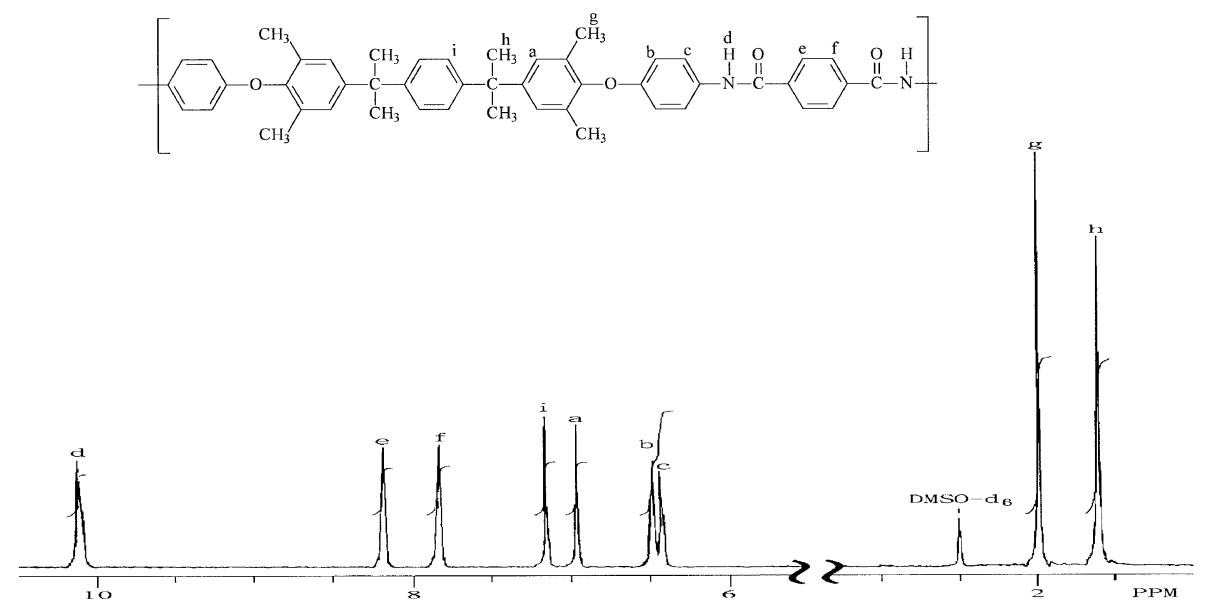

Figure 2. $400 \mathrm{MHz}{ }^{1} \mathrm{H}$ NMR spectrum taken in DMSO- $d_{6}$ at $25^{\circ} \mathrm{C}$ for PA1.

large amount of methanol with constant stirring, producing a stringy precipitate that was washed thoroughly with methanol and hot water, collected on a filter, and dried at $100^{\circ} \mathrm{C}$ under vacuum for $24 \mathrm{~h}$. The inherent viscosity of the polymer (PA1) in DMAc was $0.85 \mathrm{dL} \mathrm{g}^{-1}$, measured at a concentration $0.5 \mathrm{~g} \mathrm{dL}^{-1}$ at $30^{\circ} \mathrm{C}$. The IR spectrum (film) exhibited absorptions at $3297(\mathrm{~N}-\mathrm{H})$ and $1658 \mathrm{~cm}^{-1}(\mathrm{C}=\mathrm{O}) .{ }^{1} \mathrm{H}$ NMR (DMSO$\left.d_{6}\right): \delta(\mathrm{ppm})=10.12(\mathrm{~s}, 2 \mathrm{H}), 8.16(\mathrm{~s}, 2 \mathrm{H}), 7.83(\mathrm{~s}$, 2H), $7.15(\mathrm{~s}, 4 \mathrm{H}), 6.92(\mathrm{~s}, 4 \mathrm{H}), 6.47(\mathrm{~d}, 2 \mathrm{H}), 6.39(\mathrm{~d}$, 2H), $1.98(\mathrm{~s}, 12 \mathrm{H}), 1.62(\mathrm{~s}, 12 \mathrm{H}) ;{ }^{13} \mathrm{C}$ NMR (DMSO$\left.d_{6}\right): \delta(\mathrm{ppm})=163.90,152.16,150.37,150.13,149.05$, $148.56,144.37,131.69,131.55,129.47,129.28$, 128.92, 120.91, 117.44, 116.21, 43.94, 31.15, 16.25.

The typical ${ }^{1} \mathrm{H}$ NMR and ${ }^{13} \mathrm{C}$ NMR spectra of PA1 are shown in Figures 1 and 2, respectively.

ANAL. calcd for $\mathrm{C}_{48} \mathrm{H}_{42} \mathrm{O}_{6} \mathrm{~N}_{2}: \mathrm{C}, 80.64 \% ; \mathrm{H}, 6.49 \%$; N, 3.92\%; found : C, 78.45\%; H, 6.65\%; N, 3.67\%.

All other polyamides (PA2-PA6) were prepared using a similar procedure.

\section{Instruments}

Melting points were measured in capillaries on a Büchi apparatus (Model BUCHI 535). IR spectra were recorded in the range $4000-400 \mathrm{~cm}^{-1}$ on a JASCO IR700 spectrometer. ${ }^{13} \mathrm{C}$ and ${ }^{1} \mathrm{H}$ NMR spectra were obtained using a Joel EX-400 operating at $100.40 \mathrm{MHz}$ for carbon and $399.65 \mathrm{MHz}$ for proton. The inherent viscosities of all polyimides were measured using Ubbelohde viscometer. Elemental analysis was made (Perkin-Elmer 2400 instrument). Wide-angle X-Ray diffraction patterns were performed at room temperature with film specimens on an X-Ray diffractometer (Philips model PW 1710) using Ni filtered $\mathrm{Cu}-\mathrm{K \alpha}$ radiation $(30 \mathrm{kV}, 20 \mathrm{~mA})$. Samples for thermogravimetric analysis (ULVAC, model 7000) were heated under nitrogen or air $\left(60 \mathrm{~cm}^{3} \mathrm{~min}^{-1}\right)$ at a heating rate of $20^{\circ} \mathrm{C} \mathrm{min}^{-1}$. Differential scanning calorimetry (DSC) analysis was performed on a DuPont 2000 differential scanning calorimeter at a heating rate of $20^{\circ} \mathrm{C} \mathrm{min}^{-1}$. Tensile properties were determined from stress-strain 
Table I. Inherent viscosities, molecular weight and solubility of various polyamides

\begin{tabular}{|c|c|c|c|c|c|c|c|c|c|c|c|}
\hline \multirow{2}{*}{$\begin{array}{c}\text { Polymer } \\
\text { Code }\end{array}$} & \multirow{2}{*}{$\frac{\eta_{\text {inh }^{\mathrm{a}}}}{\mathrm{dL} \mathrm{g}^{-1}}$} & \multirow{2}{*}{$\bar{M}_{\mathrm{n}} \times 10^{-4 \mathrm{~b}}$} & \multirow{2}{*}{$\bar{M}_{\mathrm{w}} \times 10^{-4 \mathrm{~b}}$} & \multirow{2}{*}{$\mathrm{PDI}^{\mathrm{b}}$} & \multicolumn{7}{|c|}{ Solvent $^{\mathrm{c}}$} \\
\hline & & & & & NMP & DMAc & $\overline{\mathrm{DMF}}$ & DMSO & Py & THF & Cyclohaxanone \\
\hline PA-1 & 0.80 & 6.0 & 10.2 & 1.69 & ++ & +++ & ++ & ++ & ++ & ++ & + \\
\hline PA-2 & 0.68 & 2.0 & 3.8 & 1.90 & ++ & ++ & ++ & ++ & ++ & ++ & ++ \\
\hline PA-3 & 0.82 & 5.5 & 11.2 & 2.04 & ++ & ++ & +- & + & ++ & ++ & + \\
\hline PA-4 & 0.94 & 7.9 & 14.8 & 1.87 & ++ & ++ & ++ & +- & ++ & ++ & + \\
\hline PA-5 & 0.85 & 5.7 & 12.2 & 2.13 & ++ & ++ & ++ & + & ++ & ++ & ++ \\
\hline PA-6 & 0.76 & 4.4 & 8.3 & 1.89 & ++ & ++ & ++ & ++ & ++ & ++ & ++ \\
\hline $\operatorname{Ref}_{-1}{ }^{d}$ & 0.63 & $-{ }^{\mathrm{e}}$ & $-^{\mathrm{e}}$ & $-{ }^{\mathrm{e}}$ & ++ & + & +- & +- & +- & +- & +- \\
\hline $\operatorname{Ref-2^{d}}$ & 0.72 & $-^{\mathrm{e}}$ & $-^{\mathrm{e}}$ & $-{ }^{\mathrm{e}}$ & + & +- & +- & - & - & - & - \\
\hline $\operatorname{Ref}-3^{d}$ & 0.69 & $-^{\mathrm{e}}$ & $-^{\mathrm{e}}$ & $-{ }^{\mathrm{e}}$ & ++ & + & + & +- & - & +- & +- \\
\hline
\end{tabular}

${ }^{\mathrm{a}}$ Measured in DMAc at a concentration of $0.5 \mathrm{~g} \mathrm{dL}^{-1}$ at $30^{\circ} \mathrm{C} .{ }^{\mathrm{b}}$ Measured by GPC in THF, with polystyrene as standard. ${ }^{\mathrm{c}}$ Solubility: ++ : soluble at room temperature; +: soluble on heating at $70^{\circ} \mathrm{C}$;--: partial soluble on heating at $70^{\circ} \mathrm{C}$; - : insoluble on heating at $70^{\circ} \mathrm{C}$. Abbreviations: DMF: $N, N$-dimethylacetamide; THF: tetrahydrofuran; Py:Pyridine; DMSO: dimethylsulfoxide; DMAc: $N, N$ dimethylacetamide; NMP: $N$-methyl-2-pyrrolidinone. ${ }^{\mathrm{d}}$ Analogous polyamid, Ref-1-Ref-3. ${ }^{\mathrm{e}}$ Could not be soluble in THF at room temperature.

curves obtained with a Orientec Tensilon with a load cell of $10 \mathrm{~kg}$. A gauge of $3 \mathrm{~cm}$ and a strain rate of $2 \mathrm{~cm} \mathrm{~min}{ }^{-1}$ were used for this study. Measurements were performed at room temperature with film specimens $(0.4 \mathrm{~cm}$ wide, $6 \mathrm{~cm}$ long, and $c a .0 .15 \mathrm{~mm}$ thick).

\section{RESULTS AND DISCUSSION}

\section{Monomer Synthesis}

As shown in Scheme 1, the diamine BDAPD was synthesized in two steps by the aromatic nucleophilic substitution reaction of $\alpha, \alpha^{\prime}$-bis(4-hydroxy3,5-dimethyl-phenyl)-1,4-diisopropylbenzene and $p$ chloronitrobenzene in the presence of $\mathrm{K}_{2} \mathrm{CO}_{3}$, to obtain the dinitro compound (BDNPD), followed by reduction with hydrazine monohydrate/ $\mathrm{Pd} / \mathrm{C}$. The structures of the new dinitro and diamine compounds were confirmed by elemental analysis, IR, NMR spectroscopy. In IR spectra, BDAPD revealed absorption bands due to the nitro group around 1579 and $1334 \mathrm{~cm}^{-1}$. After reduction, the characteristics absorption of nitro groups disappeared and the characteristic bands of the amino groups at 3420 and $3342(\mathrm{~N}-\mathrm{H}$ stretching) and $1620 \mathrm{~cm}^{-1}(\mathrm{~N}-\mathrm{H}$ bending $)$ was observed in the IR spectrum. The NMR spectra data were listed in the experimental section. The ${ }^{13} \mathrm{C}$ NMR spectra of BDNPD and BDAPD both exhibited 13 peaks each. When the dinitro compound BDNPD was converted into diamine BDAPD, the signal at $4.64 \mathrm{ppm}$ in ${ }^{1} \mathrm{H}$ NMR spectra is peculiar to amino group.

\section{Preparation of Polyamides}

The new polyamides (PA1-PA6) were prepared by the direct polycondensation of diamine BDAPD with a series of commercial available (DA1-DA4) and synthesized (DA5 and DA6) dicarboxylic acids in NMP containing dissolved $\mathrm{CaCl}_{2}$ using triphenyl phosphite (TPP) and pyridine as condensing agents (Yamazaki reaction conditions) (Scheme 2). All the polycondensations proceeded in a homogeneous solution and the resulting polyamides were obtained with almost quantitative yield (97-99\%). The polyamides had inherent viscosities between $0.68-0.94 \mathrm{dL} \mathrm{g}^{-1}$, as summarized in The polymers exhibited number-average molecular weight $\left(\bar{M}_{\mathrm{n}}\right)$ and weight-average molecular weight $\left(\bar{M}_{\mathrm{n}}\right)$ in the range of 20000-79000 and 38000-148000, respectively. The molecular weight of the polymers was high enough to obtain flexible and tough polymer films by solution-casting from their DMAc solutions. The formation of polyamides was confirmed by IR spectroscopy. The IR spectrum of the polymers showed the characteristic absorptions of amide groups occurred around $3302-3334$ and $1651-1658 \mathrm{~cm}^{-1}$, peculiar to $\mathrm{N}-\mathrm{H}$ stretching and carbonyl stretching, respectively. Strong absorption band around $1230 \mathrm{~cm}^{-1}$ was observed and assignable to $\mathrm{C}-\mathrm{O}-\mathrm{C}$ linkage. It was observed that found values of carbon of polyamides were lower than the calculated ones for the proposed structures. Such a difference may be attributed to the amide group's hygroscopic characteristics. ${ }^{15}$

\section{Polymer Characterization}

The solubility of these polyamides was tested qualitatively $(3 \% \mathrm{wt} / \mathrm{v})$ in various solvents. The results are also shown in Table I. All of the polyamides could be easily dissolved in the test solvents including $N$-methyl-2-pyrrolidinone (NMP), $\quad N, N$ dimethylacetamide (DMAc), $N, N$-dimethylformade (DMF), dimethyl sulfoxide (DMSO), pyridine, tetrahydrofuran (THF). The good solubility was possibly governed by the structural modification through the incorporation of the flexible isopropylidene and ary- 
Organsoluble polyamides derived from BDAPD

Table II. Thermal and mechanical properties of various polyamides

\begin{tabular}{|c|c|c|c|c|c|c|}
\hline \multirow{2}{*}{$\begin{array}{l}\text { Polymer } \\
\text { Code }\end{array}$} & \multirow{2}{*}{$\frac{T_{g}{ }^{\mathrm{a}}}{{ }^{\circ} \mathrm{C}}$} & \multicolumn{2}{|c|}{$\mathrm{T}_{\mathrm{d} 10}^{\mathrm{b}}$} & \multirow{2}{*}{$\begin{array}{c}\begin{array}{c}\text { Tensile } \\
\text { Strength }\end{array} \\
\mathrm{MPa}\end{array}$} & \multirow{2}{*}{$\begin{array}{c}\text { Elongation } \\
\text { at Break } \\
\%\end{array}$} & \multirow{2}{*}{$\frac{\begin{array}{c}\text { Initial } \\
\text { Modulus }\end{array}}{\mathrm{GPa}}$} \\
\hline & & In Nitrogen $/{ }^{\circ} \mathrm{C}$ & In $\mathrm{Air} /{ }^{\circ} \mathrm{C}$ & & & \\
\hline PA-1 & 242 & 437 & 453 & 111 & 10 & 1.9 \\
\hline PA-2 & 256 & 440 & 461 & 104 & 12 & 2.1 \\
\hline PA-3 & 239 & 442 & 460 & 110 & 10 & 2.0 \\
\hline PA-4 & 252 & 452 & 463 & 113 & 10 & 1.9 \\
\hline PA-5 & 237 & 442 & 451 & 98 & 9 & 1.8 \\
\hline PA-6 & 249 & 440 & 447 & 83 & 10 & 1.7 \\
\hline Ref-1 & 215 & 455 & 450 & 80 & 7 & 1.7 \\
\hline Ref-2 & 217 & 452 & 457 & 85 & 7 & 1.7 \\
\hline Ref-3 & 229 & 463 & 460 & 90 & 7 & 1.8 \\
\hline
\end{tabular}

${ }^{\mathrm{a}}$ From the second heating trace of DSC measurements conducted at a heating rate of $20^{\circ} \mathrm{C} \mathrm{min}^{-1}$. ${ }^{\mathrm{b}} \mathrm{Temperature}$ at $10 \%$ weight loss $\left(T_{\mathrm{d} 10}\right)$ determined by TGA in nitrogen at a heating rate of $20^{\circ} \mathrm{C} \mathrm{min}^{-1}$.

lene ether groups into the polyamide structure. For comparison, polyamides Ref-1 and Ref-2 containing only one isopropylidene unit in the repeating unit were prepared. In addition, polymer Ref-3 containing hexafluoroisopropylidene unit was also synthesized as a reference. Table I also summarized the solubility

Ref-1:

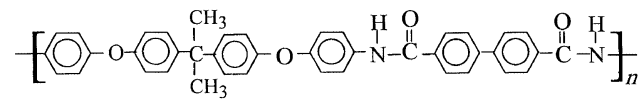

Ref-2:

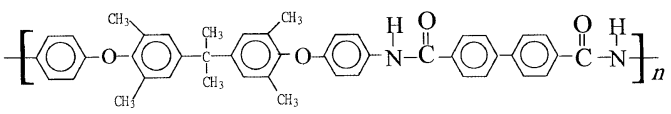

Ref-3:

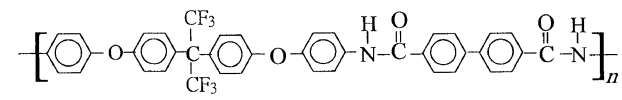

of the solubility behavior of Ref-1-Ref-3. It had been observed that polyamides Ref-1 and Ref-2 showed less solubility than their analogous polymer (PA4). This result clearly demonstrated that the presence of more isopropylidene units in the repeat unit led to an enhanced solubility. It was noted that polyamide Ref-3 containing hexafluoroisopropylidene unit in the polymer backbone also showed less solubility than polymer PA4 containing five benzene rings. It implied that the BDAPD-based polymers showed better solubility than those containing hexafluoroisopropylidene unit which was incorporated in the polymer backbone to prepare soluble polyamides. ${ }^{19}$

The crystallinity of the polyamides was examined by wide-angle X-Ray diffraction diagrams. All the polyamides exhibited fairly amorphous patterns. These results could be explained by the presence of the flexible isopropylidene and ether groups which reduced the rigidity of the polymer chain. In addition, methyl groups on the phenylene also inhibited close packing of the polymer chains. ${ }^{12,13,16}$

The thermal properties of the polyamides are tabulated in Table II. Glass transition temperatures $\left(T_{\mathrm{g}}\right.$ 's) of polyamides, determined by means of differential scanning calorimeter (DSC), were found to be in the range of $239-256^{\circ} \mathrm{C}$. No melting endotherm peak was observed from DSC traces. This also verified the amorphous nature of the polyamides. It was observed that PA2 containing bulky pendent $t$-butyl group exhibited the highest $T_{\mathrm{g}}$ value. In general, the chain rigidity was increased due to the pendent group, which restricted the free rotation of the polymer backbone. Hence, the obtained polymers showed high glass transition temperature. $^{20}$ Thermogravimetric (TG) analysis revealed that these polyamides were stable up to the temperature above $400^{\circ} \mathrm{C}$ both in nitrogen and air atmosphere. The temperatures at $10 \%$ weight loss $\left(T_{\mathrm{d} 10}\right)$, examined by TG curve, showed values reaching to $437-$ 452 and $447-463^{\circ} \mathrm{C}$ in nitrogen and air atmosphere, respectively. It is interesting to find that most of the polyamides showed higher $T_{\mathrm{d} 10}$ in air than in nitrogen. The higher $T_{\mathrm{d} 10}$ value in air may reflect the oxidation of methyl groups in polymer backbone, which forms carbonyl $(\mathrm{C}=\mathrm{O})$ groups and then causes weight gain. ${ }^{17,21-23}$ The tensile properties of the polyamide films obtained by the solution-casting are also summarized in Table II. These polymer films had tensile strength of 83-113 MPa, elongation at break of 9-12\%, and initial modulus of 1.7-2.1 GPa. Most of the films showed strong and tough natures. The data of reference polyamides (Ref-1-Ref-3) about the thermal and mechanical properties were also summarized in Table II. The mechanical properties of all polyamides (PA-1PA-6) have higher values than that of Ref-1-Ref-3 (Table II). Upon comparison with thermal properties, for example, PA-4 introducing the more isopropylidene and benzene ring in the polymer backbone had higher 
$T_{\mathrm{g}}, T_{\mathrm{d} 10}$ and tensile strength values than references Ref-1 and Ref-2 using the same diacid, 4,4'-biphenyl dicarboxylic acid (DA-4).

\section{CONCLUSIONS}

The five benzene rings-containing diamine BDAPD was successfully prepared in high purity and high yields in this study, and moderate to high inherent viscosity of new polyamides were obtained. These new polyamides are amorphous and readily dissolved in polar solvents and common organic solvents such as tetrahydrofuran. TGA and tensile measurements revealed that these polyamides showed good thermal stability and mechanical property, respectively. This study also demonstrated that these five benzene ringscontaining polyamides had better solubility than those containing only one isopropylidene unit or a hexafluoroisopropylidene linkage in the repeating unit of polyamide backbone. These polyamides could be considered as new processable high-performance polymeric materials.

Acknowledgment. We thank the National Science Council of the Republic of China for support of this work under grant NSC 89-2216-E011-008 and B.Y. Liaw for his technical assistance.

\section{REFERENCES}

1. P. E. Cassidy, “Thermally Stable Polymer", Marcel Dekker, Inc., New York, N.Y., 1980.

2. A. H. Frazer, "High Temperature Resistant Polymers", John Wiley \& Sons, Inc., New York, N.Y., 1968.

3. A. E. Lozano, J. de Abajo, J. G. de la Campa, and J. Preston,
J. Polym. Sci., Part A: Polym. Chem., 30, 1327 (1992).

4. F. Akutsu, K. Matsuo, K. Naruchi, and M. Miura, Polym. Commun., 30, 182 (1989).

5. J. A. Mikroyannidis, Polymer, 37, 2715 (1996).

6. D. J. Liaw and B. Y. Liaw, Macromol. Symp., 122, 343 (1997).

7. H. Yagci and L. J. Mathias, Polym. Prepr., (Am. Chem. Sci., Div. Polym. Chem.), 39, 262 (1998).

8. I. K. Spiliopoulos, J. A. Mikroyannidis, and G. M. Tsivgoulis, Macromolecules, 31, 522 (1998).

9. M. L. Xie, Y. Oishi, M. A. Kakimoto, and Y. Imai, J. Polym. Sci., Part A: Polym. Chem., 29, 55 (1991).

10. Y. Delaviz, A. Gungor, J. E. McGrath, and H. W. Gibson, Polymer, 34, 210 (1993).

11. M. Yamashita, M. A. Kakimoto, and Y. Imai, J. Polym. Sci., Part A: Polym. Chem., 31, 1513 (1993).

12. D. J. Liaw and B. Y. Liaw, J. Polym. Sci., Part A: Polym. Chem., 36, 1069 (1998).

13. D. J. Liaw and B. Y. Liaw, Macromol. Chem. Phys., 199, 1473 (1998).

14. D. J. Liaw, P. N. Hsu, and B. Y. Liaw, High Perform. Polym., 13, S257 (2001).

15. D. J. Liaw, B. Y. Liaw, and C. M. Yang, Macromolecules, 32, 7248 (1999).

16. D. J. Liaw, B. Y. Liaw, and Y. S. Chen, Polymer, 40, 4041 (1999).

17. D. J. Liaw, B. Y. Liaw, J. R. Chen, and C. M. Yang, Macromolecules, 32, 6860 (1999).

18. D. J. Liaw, B. Y. Liaw, and C. Y. Chung, Macromol. Chem. Phys., 200, 1023 (1999).

19. D. J. Liaw and K. L. Wang, J. Polym. Sci., Part A: Polym. Chem., 34, 1209 (1996).

20. V. V. Korshak, S. V. Vinogradova, and Y. S. Vygodski, J. Macromol. Sci., Rev. Macromol. Chem., C11, 45 (1974).

21. M. Bruma, J. W. Fitch, and P. E. Cassidy, J. Macormol. Sci., Rev. Macromol. Chem. Phys., C36, 119 (1996).

22. J. P. Luongo, J. Polym. Sci., 42, 139 (1960).

23. B. Baum, J. Appl. Polym. Sci., 2, 281 (1959). 